Recibido: $17-02-2016$ Aceptado: 23-02-2016

Palabras clave: Lectura, homo videns, aprendizaje. Keywords: Reading, homo videns, learning.

Manuel Arboccó de los Heros manoloarbocco@gmail.com UNIFE- UIGV

\section{La lectura en la era audiovisual: problemas y posibilidades}

\section{Reading in audiovisual era: problems and opportunities}

Manuel Arboccó de los Heros

\section{RESUMEN.}

Estamos viviendo tiempos donde hábitos saludables como la lectura profunda, la escritura correcta y el debate alturado e inteligente están dejando de practicarse. La sociedad postmoderna, tecnocrática y mediática está apropiándose de ese espacio privado, introspectivo y reflexivo que caracteriza al verdadero homo sapiens. De ahi que ahora los estudiosos de la sociedad vengan hablando del "homo videns" o del "homo ciber" y de esta sociedad como la "sociedad ligth" cuando no "del vacío".

Nos preocupa el decaimiento de la palabra, de la lectura y sus posibilidades y el aumento de intereses mediáticos como la televisión tan venida a menos en las últimos tres décadas, y no solo en el Perú sino en otras latitudes.

Esperamos que estas reflexiones sobre el hombre, la lectura, el conocimiento, sean de interés y dé impulso a otras nuevas.

ABSTRACT. We are living times where healthy habits as the deep reading, the correct writing and the smart and intelligent debate are leaving of practice. Postmodern, technocratic society and media is appropriating that private, introspective and reflective space that characterizes the true homo sapiens. That is why now scholars society come talking about "homo videns" or "homo cyber" and this society as "light society" and not "of the vacuum".

We are concerned of the decay of the word, the reading and their possibilities and the increase of media interests as the television so come at least in the last three decades, and not only in Peru but in other latitudes. We hope that these reflections of the man, the reading, the knowledge be of interest and give impetus to new ones. 


\section{El niño ante la tecnología}

$\mathrm{E}$ $\mathrm{n}$ un trabajo anterior propusimos el siguiente ejercicio (Arboccó, 2015). Acérquenle a un(a) niño(a) pequeño(a) un libro y un celular y fijense por cuál de los dos se inclina el pequeño. Lo más probable es que termine eligiendo el celular y esto no tiene nada de raro al ser un aparato que permite la interacción, tiene efectos sonoros, brinda imágenes y juegos. Es aquí donde el adulto ingresa en escena. Como adultos y personas racionales sabemos que el principal aspecto que necesita la humanidad en su proceso de formación es la palabra, el verbo, la argumentación. La lectura y luego la escritura son tareas exclusivamente humanas que nos permiten adaptarnos, socializar y solucionar muchos problemas. Y como adultos buscamos que desde pequeños, los humanos aprendan la importancia de leer y el placer de hacerlo, situación que nos permitirá acercarnos a la civilización, el entendimiento y la cultura. Pero hoy los niños tienen desde muy temprana edad -algunos ya desde bebés- acceso al celular, la tablet y la TV y aprender a emplearlos mucho antes que a leer, $y$ vemos que sus cerebros se están acostumbrando a no leer, con lo que puede verse limitada su imaginación, su desarrollo verbal, su capacidad de análisis y de ordenar las ideas (Sartori, 2004).

El niño necesita de la interacción con personas y objetos a fin de sacar provecho de las nuevas aptitudes que la maduración cerebral hace posible. Esta estimulación psicoafectiva y física en la temprana infancia se traduce en un mayor nivel de maduración neurológica y, por lo tanto, en una mayor capacitación intelectual (Arboccó, 2016).

En una entrevista periodística al escritor y profesor universitario Jorge Eslava, nos recuerda que "una buena lectura es una experiencia de inteligencia e imaginación. También de sensibilidad. Creo que desarrollar la lectura desde niños cultiva y modela el espiritu" (Eslava, 2015, p.7). Por su parte, para la psicóloga y escritora Pilar González Vigil "la lectura desarrolla la imaginación de los niños, y ahora se sabe, gracias a las investigaciones en el campo de las neurociencias, que muestro cerebro no diferencia entre lo que imaginamos y lo que experimentamos en la realidad. Entonces, en su mente los lectores viven la bistoria junto a los personajes" (González Vigil, 2015, p. 7). Ambos comentarios coinciden en lo fundamental que es formar el hábito de la lectura en las personas y como todo buen hábito debe ser formado desde pequeño. Porque el niño solo no lo hará, él se dirigirá hacia el celular (que se lo prestan siempre que lo pide) o hacia la TV (que se la encienden a toda hora) cuando de pronto tendríamos que acercarlo creativa, divertida $y$ amorosamente al texto, al libro. La lectura (sobre todo su práctica desde pequeños) promueve el ejercicio de la atención, la imaginación, la creatividad, potencia el pensamiento abstracto y el desarrollo del lenguaje (Beltrán y Seinfeld, 2012).

Hay quienes sostienen también que la lectura nos lleva a aprender muchas otras cosas, a ser más tolerantes y nos da lecciones morales, inclusive. Por su parte, el polígrafo Marco Aurelio Denegri la considera "el único vicio saludable", dice así: "Se trata, empero, de una medicina que, curiosamente, satisface un vicio; sólo que un vicio saludable, el único vicio saludable: el de la lectura" (Denegri, 2011, p.70).

\section{La introversión y los chimpancés}

Lamentablemente una dimensión humana que se va perdiendo es la introversión (Arboccó, 2014). La introversión es una orientación psíquica por la cual prescindiendo de los estímulos externos buscamos penetrar, adentrarnos, en nosotros mismos. Pero hoy en día la introversión y circunstancias relacionadas como la introspección, la contemplación y la reflexión personal son situaciones difíciles de encontrar, no son muy practicadas por no desearlo o quizá por no poder hacerlo.

Estamos echados (vertidos) hacia afuera, hacia el estímulo exterior. En ese sentido no 
abunda la introversión sino la extraversión (vertido hacia afuera). El individuo promedio está muy atento a lo que pasa afuera, al estímulo y si este es intenso, mejor. Por ejemplo, hoy está de moda el conductor de radio que grita, que habla rápido, que pone y pone canciones, una tras otra, sin pausa alguna, con publicidad que aparece y cual metralleta, dispara palabras incesantemente. También está la TV con sus cientos de horas de contenidos insustanciales, superficiales pero con un rating asombroso. Además, con toda la tecnología a disposición de este individuo que ve así "entretenido" su cerebro y sus sentidos.

Los chimpancés cuando ya no ven a nadie fuera de su jaula, o cuando ya nadie les tira algo de comer y cuando ya no hay ruido fuera, sencillamente se duermen porque son incapaces de ensimismarse, son incapaces de reflexionar, de pensar. Esto no es de extrañar, finalmente son chimpancés y si bien tienen una serie de habilidades y pueden aprender muchas cosas, hay estados que no poseen, como la consciencia, o capacidades que desconocen como la metacognición, la introspección o la autocontemplación. Sin embargo vemos que estos fenómenos empiezan a darse con relativa frecuencia en los seres humanos y eso es preocupante. Vemos alumnos que se duermen con mucha facilidad cuando "no hay acción" en clase o cuando la tarea involucra una reflexión profunda, y no digamos una reflexión personal. Se duermen porque el silencio (necesario para reflexionar) y la pausa (necesaria para tramitar las ideas o para ordenarlas) los encuentra carentes de lo que se ha dado en llamar el mundo interior, entonces al faltar el estímulo ambiental, el cerebro se aburre y el individuo se apaga, sobre todo cuando no hay una importante cuota intelectual.

Muchas personas hoy, de pronto más que ayer, ven difícil cuando no inútil el ejercicio de la introspección, la reflexión y la necesaria introversión. Una característica encontrada en grandes creadores es la capacidad de aislarse, de alejarse del ruido y la masa. Como diría el notable escritor Franz
Kafka "necesito alejarse de mi para escribir", o Cicerón "la observación de la naturaleza y la meditación ban generado el arte". Hoy se apuesta más bien por la atención a lo externo, a lo mediático, por eso -entre otras cosas- fenómenos como la TV basura proliferan y generan más adeptos. Y cuando ese hombre carente de dentrura no encuentra esos estímulos ruidosos y luminosos, se duerme, como el chimpancé.

Hoy se habla tanto de niños y adolescentes aburridos (y adultos también), de niños y jóvenes con problemas de atención y concentración, de personas deprimidas, desatentas, distraídas, mirando hacia sitios equivocados, buscando donde no hay que buscar, mirando estímulos brindados por los medios que no estimulan realmente y hasta nos empobrecen cognitiva y afectivamente (Sartori, 2004), consideramos que la lectura es un pasatiempo enriquecedor, que de hacerse un hábito consideramos puede convertirse en un escudo protector, de algunos de los males de la sociedad. Es una vacuna contra la estupidez, el aburrimiento, la chabacanería y el miedo. En este refugio dejamos volar nuestra imaginación, potenciamos nuestra concentración, estimulamos nuestro pensamiento y nuestras capacidades lingüísticas, además de la inteligencia general y el nivel de conocimientos.

\section{De homo sapiens a homo videns}

En anterior oportunidad (Arboccó, 2015) consideramos como en el texto Homo videns: la sociedad teledirigida (2004), el politicólogo italiano Giovanni Sartori analiza el peligro de exponer a los niños (el los llama los video-niños) ante la televisión basura y nos deja una serie de afirmaciones y estadísticas que bien pueden ser tomadas en cuenta en muchas realidades sociales, las mismas que están debidamente planteadas y fundamentadas en la obra mencionada. Por ejemplo indica que el niño ensimismado con la TV no lee; la TV modifica radicalmente y empobrece el aparato cognoscitivo del homo sapiens, el niño formado en la imagen se reduce a ser un hombre 
que no lee, luego ese adulto sólo responderá a estímulos audiovisuales (Sartori, 2004). Además nos recuerda que el acto de ver está atrofiando la capacidad de entender, que el hombre que lee está decayendo rápidamente y lo peor de todo es que (en este mundo actual pareciera que) "ya no se necesita leer".

Sartori señala investigaciones indicando que un joven antes de terminar su adolescencia habrá observado horas y horas de telebasura (Sartori, 2004). Ese niño luego se transformará en un adulto empobrecido, que no lee, que responde a estímulos casi exclusivamente audiovisuales. Entre los mecanismos psicológicos de respuesta ante la telebasura están: la identificación con ciertos personajes, la imitación, la indirecta agudización de ciertos temas cuando son tratados de forma superficial y sin asesoría profesional, la asociación incorrecta de ciertos estímulos (ejemplo violenciacotidianidad, mujer-objeto sexual, felicidadconsumismo, homosexualidad-enfermedad, amor de pareja-sufrimiento necesario, entre otros); también la desensibilización ante el dolor ajeno y la vulgaridad. La enorme influencia social de la tv y otros medios multiplica de forma exponencial los efectos negativos de este tipo de mensajes (Sartori, 2004).

De esta forma vemos cómo los medios de comunicación aportan a la construcción (y destrucción) de modos de ser, de modelos de comportamientos individuales y colectivos. Nos animamos a afirmar que así se van formando modelos pobres, incultos y dependientes de las sensaciones (imágenes, sonidos) descuidando los estímulos ligados al pensamiento (la razón y la lógica). Pensamos que la lectura es una herramienta de protección contra esta época de aparatos y pantallas, de extraversión y de estimulación externa.

\section{El maltrato al lenguaje y al idioma}

Hace algunos años, un familiar, por entonces incipiente adolescente, nos mandó un mensaje de texto vía celular y yo no lo pude leer. Fue una mezcla de sorpresa e impotencia. Luego, poco a poco, hemos visto desde la Cátedra Universitaria la facilidad con la que no pocos estudiantes lesionan el buen discurso y la buena gramática. Esto despierta entonces el interés por investigar sobre este nuevo tipo de lenguaje que es el "lenguaje del chat" o $e l$ "lenguaje de watsapp". Sorprende que no muchos se preocupen por esto: será quizá un fenómeno nuevo o difícil de abordar también. Luego oímos a algunos entendidos en el lenguaje y el manejo de los términos así como lingüistas de carrera, que mientras este conjunto de símbolos cumpla el papel principal del lenguaje, refiriéndose al de la comunicación, todo marcha bien. Uno envía, el otro recibe, hay un código, que llega por un canal, el receptor lo comprende y responde y así hasta el infinito o la muerte o hasta que se corte el internet, que para el caso de los chicos de hoy es lo mismo.

Pero ¿y qué hay de las otras posibilidades del lenguaje que quedan de lado? Además de la comunicacional, el lenguaje presenta otras funciones. Karl Bühler (lingüista y filósofo alemán, 1879-1963) nos enseñó hace tiempo que existe una función expresiva (por ejemplo, "siento que esta semana que ba pasado ba sido muy provechosa") y una apelativa u operativa ("debes dejar de buir del problema $y$ encararlo de una buena vez.").

Por su parte el lingüista y fonólogo ruso Roman Jakobson (1896-1982) nos hablaba de funciones secundarias del lenguaje, pero no por eso desestimables, como la función fática (iniciar, prolongar, interrumpir o finalizar una conversación o bien sencillamente comprobar si existe algún tipo de contacto), la función poética ("inventarte es mi forma de creerte", poema Mejor te invento de Mario Benedetti) y la función metalingüística (usar el lenguaje para hablar acerca del lenguaje, a lo Wittgenstein por ejemplo).

Es importante reflexionar que inclusive dentro de la función comunicativa el lenguaje "moderno" tampoco permite comunicarse con todos ya que es casi un dialecto entre quienes 
lo emplean. Es su propio gran código -aunque reducido dicho sea de paso- con el que buscan distinguirse y alejarse.

Pensamos que se sacrifica absurdamente estas otras funciones nobles, elaboradas, estéticas e inteligentes, por emplear -ya sin esfuerzo- este minúsculo grupo de opciones. A esto se suma la enorme ayuda embrutecedora de los medios (léase radio, televisión, prensa escrita) para no necesitar esforzarse por levantar nuestro subterráneo hablar y escribir. Si dejamos de leer y dejamos también de escribir (como viene pasando), perdemos maravillosas oportunidades de desarrollo intelectual y personal. Nos apena observar como un jovencito peruano promedio hoy tiene un vocabulario muy reducido y emplea poco del mismo ("le faltan palabras para expresar lo que quiere"), cuando en el DRAE (Diccionario de la Real Academia Española) existen cerca de 100,000 palabras.

\section{El interés masivo por la "caja boba" y el descuido de los padres por la cultura de sus hijos}

"La televisión ba becho maravillas por mi cultura. En cuanto alguien enciende la televisión, voy a la biblioteca y me leo un buen libro"

Groucho Marx

La TV basura parecer ser el medio de entretenimiento general para la juventud ( $y$ no solo la más pobre), en un proceso que refuerza el consumismo, lo superficial y lo chabacano. Las cadenas televisivas han ido produciendo ciudadanos que muy poco saben y que se interesan por banalidades, y no son muchos los jóvenes que se percatan de esto. Vemos con pena cómo cientos darían la vida por ser parte de uno de los realitys de moda.

Entonces, es obvio que los medios de (in) comunicación aportan a la construcción de ciertos modos de ser. Nos animamos a afirmar que así se van formando modelos superficiales, incultos y dependientes de las sensaciones descuidando los estímulos ligados al pensamiento y la razón.

¿Qué nos ofrece esta TV actual? Historias cotidianas, las cuáles son presentadas como tremendas historias de vida; mucha violencia, el desprecio por derechos fundamentales como el honor, la dignidad o la presunción de inocencia, la idea de que lo importante es ser famoso sea como sea; la glorificación del cuerpo en desmedro de lo intelectual y lo moral, la pérdida de la intimidad y su protección, así como el olvido del comportamiento cívico y amable para con otro ser humano.

Hoy, lamentablemente, el modelo reconocido no es el sujeto más inteligente, el más solidario o el más estudioso, por el contrario es el más gracioso, la de mejor trasero, el más matón, la más histérica, el más escandaloso o el futbolista que tiene más dinero. Fijémonos en eso llamado "rating". Son los nuevos modelos de esta preocupante sociedad light. La publicidad televisiva recibida acríticamente instala al público infantil y juvenil en la superficialidad vital, el embrutecimiento y la estrechez mental (Arboccó \& O'Brien, 2012). A estar atentos con lo que dejamos entrar a casa vía TV. Lamentablemente muchos papás observan extasiados horas y horas de esta TV basura ¿cómo entonces se podrá inculcar en los hijos un gusto por la lectura y el inteligente esparcimiento si los progenitores y el resto de la familia son un constante ejemplo de consumidores de estos tontos y vulgares espacios?

\section{Reflexión final}

\section{Leer, sobre todo leer}

En esta sociedad tecnocrática, de banalidades y chismerías, que idolatra pantallas e iguala el éxito con tener dinero o salir TV, es fundamental que promovamos el interés por la lectura en los más jóvenes y este gusto por la lectura se logra en el 
niño pequeño cuando se le lee, en un ambiente cómodo, lúdico y afectuoso. Ese niño que se acerca positivamente al libro seguirá con él luego, ya de mayor, y estimulará constantemente su cerebro con palabras, historias e ideas.

El Plan Lector (una buena idea) debe mejorarse y potenciarse. Solo así, acercando al estudiante a la enciclopedia, al cuento, a la novela y al libro, podemos pensar que las futuras generaciones desarrollarán la interioridad y su mundo interno, hoy tan estimulado por efectos mediáticos, muchas veces nocivos.

Una gran cantidad de padres necesitarían una consejería mínima de cómo criar a sus hijos. Una crianza que involucre el aspecto cultural desde la más tierna infancia. El papel de la lectura, el teatro, el estudio y las artes en la formación personal ya ha sido investigado y están documentados los efectos positivos que, a corto y largo plazo brindan a los seres humanos

El lingüista y profesor universitario Luis Jaime Cisneros (1921-2011) decía que el único mérito que podía reclamar como propio era la lectura. Recordaba haber crecido en una casa llena de libros y cada vez que su padre le leía, párrafos del Quijote, eso era buen anticipo de los alimentos.

En las aulas hoy vemos jóvenes con dificultades para leer, que prácticamente ya no escriben pero son diestros en el manejo de sus pulgares, con argumentos falaces y rudimentarios a la hora de defender una posición, pegados todo el día a unos audífonos y con serias limitaciones para concentrarse sin ellos y hasta para hacer algún mínimo cálculo mental. Todo esto requiere exigir a nuestro cerebro y si no lo habituamos desde pequeños, probablemente ya de grandes será casi imposible. Si esto lo observamos en las aulas universitarias ¿qué pasará en quienes no se han insertado en el mundo académico? El maestro Jorge Luis Borges decía que de los diversos instrumentos inventados por el hombre, el más asombroso era el libro; todos los demás eran extensiones de su cuerpo, pero sólo el libro es una extensión de la imaginación y la memoria. A tenerlo en cuenta.

\section{Referencias}

Arboccó, M. \& O’Brien, J. (2012). Impacto de la televisión basura en la mente y la conducta de niños $y$ adolescentes. Avances en Psicología, UNIFÉ, Lima, Vol. 2. pp. 43-57. Disponible en versión online en: http://www.detrasdelacortina. com.pe/download/Impactotvbasura.pdf

Arboccó de los Heros, M. (16 de noviembre del 2014). La introversión y los chimpancés. Diario Oficial El Peruano, p. 12, Disponible en: http://www.entornointeligente.com/ articulo/4148466/PERU-La-introversiony-los-chimpances-16112014.

Arboccó de los Heros, M. (2015). Neurociencias, educación y salud mental. Educación, $N^{\circ}$ XXI, p. 11-19. Lima: Facultad de Ciencias de la Educación de la Universidad Femenina del Sagrado Corazón.

Arboccó de los Heros, M. (1 junio del 2016). Piaget, los niños y el desarrollo cognitivo. Diario Oficial El Peruano, p. 12, Disponible en: http://www.elperuano.pe/noticia-piagetlos-ninos-y-desarrollo-cognitivo-41501.aspx Beltrán, A. y Seinfeld, J. (2012). La trampa educativa en el Perú. Cuando la educación llega a muchos pero sirve a pocos. Lima: Fondo Editorial de la Universidad del Pacífico.

Denegri, M.A. (2011). Esmórgasbord. Lima: Fondo Editorial de la Universidad Inca Garcilaso de la Vega.

Eslava. J. (1 de marzo del 2015). La lectura en los niños. Entrevista del Diario El Comercio, Suplemento El Dominical, p. 6-7.

González Vigil, P. (1 de marzo del 2015). Narrar para inspirar. Entrevista del Diario El Comercio, Suplemento El Dominical, p. 11.

Sartori, G. (2004). Homo videns. La sociedad teledirigida. España: Editorial Taurus. 